\title{
Pelatihan Penggunaan Sistem Informasi Inventaris Bagi Petugas Poliklinik Di Kawasan Pemulung Rangkah Surabaya
}

\author{
Faried Effendy*, Barry Nuqoba, Army Justitia, dan Indah Werdiningsih \\ Fakultas Sains dan Teknologi Universitas Airlangga, Surabaya \\ *E-mail: faried-e@ fst.unair.ac.id
}

\begin{abstract}
Abstrak - Poliklinik "Pemulung" merupakan yang poliklinik menyediakan layanan pengobatan dan obat-obatan gratis bagi masyarakat di area kampung Pemulung. Dari sisi operasional, poliklinik dibantu oleh tenaga medis dari Bulan Sabit Merah Indonesia (BSMI) dan obat-obatan dari Yayasan Dana Sosial Al-Falah (YDSF), sedangkan admin poliklinik berasal dari warga sekitar. Berdasarkan hasil wawancara dan observasi disimpulkan bahwa yang dibutuhkan oleh para mitra adalah wawasan dan keterampilan dalam kegiatan inventaris barang, terutama pengelolaan inventarisasi, pengelolaan arsip dan aset serta suatu aplikasi yang dapat membantu admin poliklinik dalam merekap aset dan membuat laporan perminggunya. Berdasarkan permasalahan tersebut, kegiatan pengabdian masyarakat ini bertujuan untuk memberikan pelatihan dan pemberian pengetahuan mengenai proses inventarisasi yang benar dan optimal dengan baik menggunakan Sistem Informasi Inventaris Barang dan juga microsoft excel. Sistem informasi dibangun berbasis web dan diset secara offline untuk kemudahan dan fleksibilitas. Dari hasil pre test dan post test disimpulkan bahwa telah terjadi peningkatan wawasan dan pengetahuan mengenai sistem informasi dan materi excel yang diajarkan.
\end{abstract}

Kata Kunci_Poliklinik Pemulung, Sistem Informasi Inventaris, Pelatihan

\begin{abstract}
The "Scavenger" polyclinic is a polyclinic that provides free medical treatment and medicine for people in the scavenger village area. From the operational side, the polyclinic is assisted by medical personnel from the Indonesian Red Crescent (BSMI) and medicines from the Al-Falah Social Fund Foundation (YDSF), while the polyclinic admin comes from residents. Based on the results of interviews and observations, it is concluded that what partners need is insight and skills in inventory activities, especially inventory management, archive and asset management, and an application that can help polyclinic administrators recapitulate assets and making weekly reports. Based on these problems, this community service activity aims to provide training and provide knowledge about the correct and optimal inventory process using the Goods Inventory Information System and also Microsoft Excel. The information system is web-based and set up offline for simplicity and flexibility. From the pre-test and post-test results, it is concluded that there has been an increase in insight and knowledge about the information system and excel material being taught.
\end{abstract}

Keywords — Scavenger Polyclinic, Inventory Information System, Training

\section{PENDAHULUAN}

Kemiskinan masih menjadi perhatian khusus dan sering menjadi trending topic [1]. Setiap warga negara berhak untuk mendapatkan fasilitas kesehatan yang baik, dengan kata lain adalah tidak hanya tugas pemerintah untuk menciptakan kondisi dan fasilitas untuk masyarakat yang dikategorikan miskin, namun kewajiban semua pihak termasuk swasta.

Poliklinik "Pemulung" merupakan poliklinik yang berada di kawasan makam Rangkah, Kelurahan Tambakrejo, Kecamatan Simokerto, Kota Surabaya. Poliklinik ini berdiri atas inisiatif Yayasan Dana Sosial A-Falah (YDSF) dan Bulan Sabit Merah Indonesia (BSMI). Dengan bantuan tenaga medis dari BSMI dan obat-obatan dari YDSF, poliklinik memberikan layanan kesehatan secara gratis pada masyarakat di sekitar makam Rangkah. Sampai dengan Pebruari 2019 jumlah pasien yang terdaftar pada poliklinik berkisar 300 pasien, namun masih belum memiliki tempat yang permanen dan hanya difasilitasi untuk menggunakan Balai RW sebagai tempat beroperasi tiap dua kali seminggu, yakni setiap hari selasa dan jum'at mulai jam 4 sore sampai selesai. Berdasarkan survei awal yang telah dilakukan pada poliklinik "Pemulung", diketahui bahwa kegiatan inventaris pada poliklinik masih dilakukan secara manual. Selain itu, petugas poliklinik tidak memiliki kompetensi dalam hal pengetahuan inventaris, terlebih dalam membuat laporan inventaris.

Inventaris adalah barang persediaan untuk dijual dan bahan baku yang digunakan untuk menghasilkan barang dan merupakan aset bisnis yang berharga [2]. Petugas inventaris membantu mengelola, mengawasi dan memelihara persediaan produk dan peralatan. Deskripsi pekerjaan petugas inventaris melibatkan pelacakan semua produk dan 
persediaan, memastikan bahwa stok diatur, dan membantu dalam pembongkaran dan pemrosesan pengiriman [3]. Persediaan Inventaris bertujuan untuk memberi manfaat kepada pegawai sebagai perlengkapan kantor dan demi lancarnya aktifitas kerja pegawai.

Skill atau keterampilan teknis merupakan hal mutlak yang wajib dimiliki oleh seorang pekerja. Skill dapat dimiliki secara otodidak maupun melalui pelatihan. Ada 2 jenis skill yakni hard skill dan soft skill. Hard skill merupakan kemampuan yang dapat diajarkan atau rangkaian keterampilan yang mudah diukur. Hard skill didefinisikan juga sebagai kemampuan teknis yang sesuai dengan pekerjaan. Hard skill biasanya diperoleh melalui pembelajaran di kelas, dalam kursus online, melalui buku dan materi lain, atau di tempat kerja. Soft skill merupakan ragam kemampuan dalam berkomunikasi dan bersosialisasi [4]. Berdasarkan latar belakang tersebut, maka perlu untuk dilakukan pelatihan skill mengenai inventarisasi untuk meningkatkan kompetensi petugas poliklinik.

\section{ANALISIS SITUASI}

Mitra pada kegiatan pengabdian pada masyarakat ini adalah warga kampung Pemulung yang bertangung jawab sebagai admin atau petugas poliklinik.

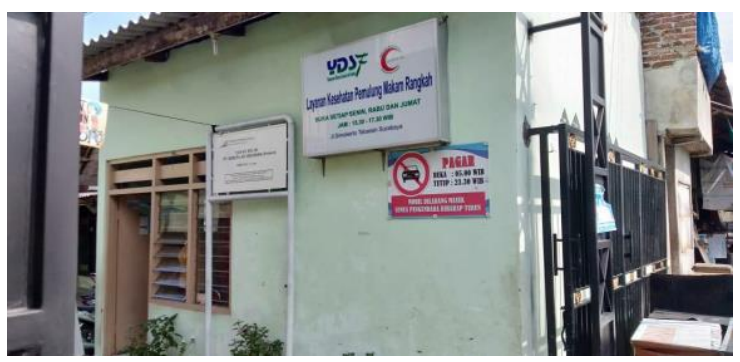

Gambar 1. Poliklinik Pemulung

Admin poliklinik merupakan orang yang bertanggung jawab terhadap aset yang dimiliki poliklinik, Setiap minggunya admin melakukan pendataan obat dan kehadiran dokter untuk diserahkan pada pihak YDSF dan BSMI. Pendataan dilakukan dengan mencatat di sebuah buku dan kertas kehadiran, sementara untuk mengetahui obat yang habis atau kadaluarsa, admin harus mendata langsung pada rak obat untuk dimintakan obat baru pada YDSF. Berdasarkan hasil observasi dan wawancara diketahui bahwa masalah yang dihadapi admin adalah pengetahuan dan keterampilan yang masih kurang dalam hal inventaris barang, serta cara pengarsipan yang masih seadanya. Admin mengakui bahwa pengetahuan dan keterampilannya selama ini didapat secara otodidak, sehingga banyak hal penting yang belum diketahui dan dikuasai. Salah satu dampak yang telah terjadi akibat cara pengarsipan admin poliklinik diantaranya adalah banyaknya barang/ asset yang hilang, tidak adanya buku catatan aset, letak/posisi asset yang tidak jelas dan masih banyak persoalan lain.

Dengan adanya pelatihan dan pemberian pengetahuan mengenai proses inventarisasi yang benar dan optimal dengan baik menggunakan Sistem Informasi Inventaris Barang dan microsoft excel, diharapkan dapat meningkatkan wawasan dan kompetensi dari admin poliklinik selaku mitra pengabdian pada masyarakat ini.

\section{SOLUSI DAN LUARAN}

Sebelum Pengabdian pada masyarakat dilaksanakan, tim panitia berkoordinasi dengan mempersiapkan semua hal yang terkait. Tim Pengabdian pada masyarakat terdiri dari dosen, mahasiswa Fakultas Sains dan Teknologi Universitas Airlangga. Persiapan yang dilakukan oleh tim meliputi beberapa aspek diantaranya: akademik, administrasi, dan non-akademik. Aspek akademik meliputi: pembicara, file PPT, komputer/laptop untuk peserta, dan lembar monitoring/penilaian. Persiapan aspek administrasi meliputi lembar presensi, sertifikat untuk peserta, dan keperluan pertanggungjawaban keuangan. Aspek non- akademik meliputi tempat pelatihan, proyektor, dan makanan.

Pelatihan dilakukan di balai terbuka milik warga, diawali dengan pre test tentang pengetahuan warga dan admin poliklinik tentang sistem informasi dan microsoft excel. Dilanjutkan dengan bimbingan terstruktur. Pelatihan ini diikuti oleh, 1 admin dan peserta dari warga sekitar makam Rangkah yang antusias mengikuti materi. Karena keterbatasan tempat pelatihan, dan sumberdaya (laptop) yang dimiliki, maka peserta dibatasi sebanyak 6 orang saja (1 Admin dan 5 warga sekitar).

Bimbingan terstruktur dilaksanakan menggunakan beberapa metode pendekatan yang tujuan utamanya adalah mitra dapat memahami materi yang disampaikan, serta dapat benar-benar mempraktekkan dan merasakan manfaat dalam peningkatan kompetensi [5]. Berikut adalah metode pendekatan yang dilakukan:

1. Metode ceramah

Metode ceramah dilakukan pada tahapan pemberian pengetahuan dan ketrampilan yang aplikatif. Pada tahapan ini, metode ceramah diberikan dalam bentuk teoritis mengenai dasardasar inventaris. Mitra diajarkan tentang dasar-dasar proses inventarisasi, khususnya pengelolaan inventarisasi dan pengelolaan arsip dan aset. Salah satu yang disampaikan adalah tentang mekanisme penomoran aset, penyimpanan dokumen ke dalam ordner, pengelompokan dokumen/arsip, mekanisme peminjaman dan pengembalian aset serta dokumentasi aset masuk dan keluar. 
Jati Emas (Jurnal Aplikasi Teknik dan Pengabdian Masyarakat) KESEHATAN \& KEDOKTERAN Vol. 5 No. 1 Maret 2021 - e. ISSN: 2550-0821

\section{Metode praktek dalam bimbingan}

Pada tahapan ini, seluruh tahapan yang sudah dijelaskan pada bagian sebelumnya dipraktekkan agar mitra tidak hanya bertambah wawasannya namun juga meningkat ketrampilannya. Karena mitra dirasa masih awam dengan penggunaan Sistem Informasi, maka dasar-dasar keterampilan pembuatan laporan dengan menggunakan software microsoft excel menjadi pembuka dalam mengenalkan konsep laporan terkomputerisasi, beberapa fungsi yang kerap digunakan dalam membuat laporan juga diperkenalkan dan dipraktekkan oleh peserta, termasuk dalam pemberian instruksi penggunaan aplikasi sistem informasi akan dilakukan step by step sampai mitra mahir menggunakannya.

\section{Metode pemberian modul}

Seluruh materi yang disampaikan dan dipraktekkan oleh mitra didokumentasikan dalam sebuah modul agar mitra dapat mempelajari ulang semua yang telah diajarkan. Modul ini kemudian dibagikan kepada peserta dan pihak poliklinik untuk di jadikan sebagai dokumen poliklinik.

Kegiatan pengabdian pada masyarakat ini menggunakan pendekatan metode Focus Group Discussion (FGD), materi-materi yang disampaikan mencakup pembekalan peserta mengenai pengelolaan inventarisasi dan pengelolaan arsip dan aset. Penerapan metode FDG cukup efektif, dan materi yang disampaikan dapat diterima dengan baik.

Kegiatan evaluasi dilaksanakan dengan menggunakan metode survei melalui kuesioner untuk mengetahui apakah materi yang disampaikan sudah dapat dipahami oleh mitra [6], [7]. Kuesioner juga berfungsi untuk mengetahui berapa banyak mitra yang mempraktekkan materi yang diperoleh, serta berapa besar manfaat yang diperoleh mitra. Saat dilakukan sesi tanya jawab mengenai program yang diusulkan oleh masyarakat apabila dilakukan program pengabdian masyarakat lagi, masyarakat meminta untuk diberikan pelatihan di bidang pemasaran, khususnya pemasaran online berbasis marketplace. Proses dan hasil kegiatan dapat dilihat pada Gambar 2 - 5.

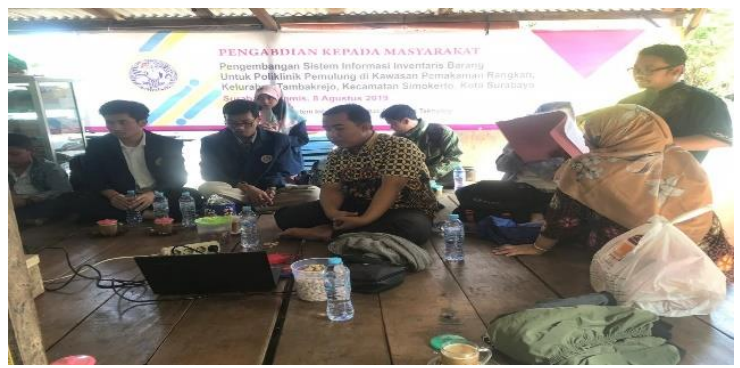

Gambar 2. Penyampaian materi

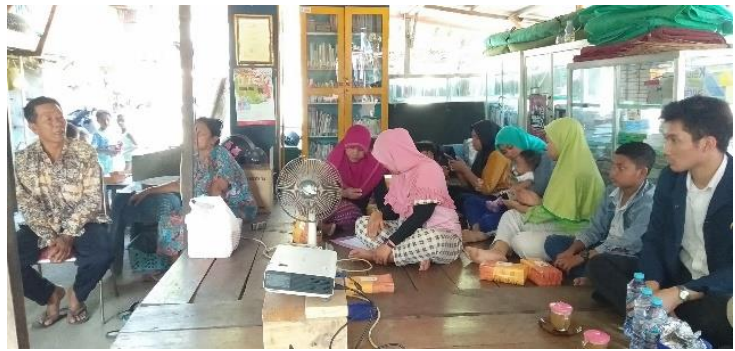

Gambar 3. Tempat pelatihan

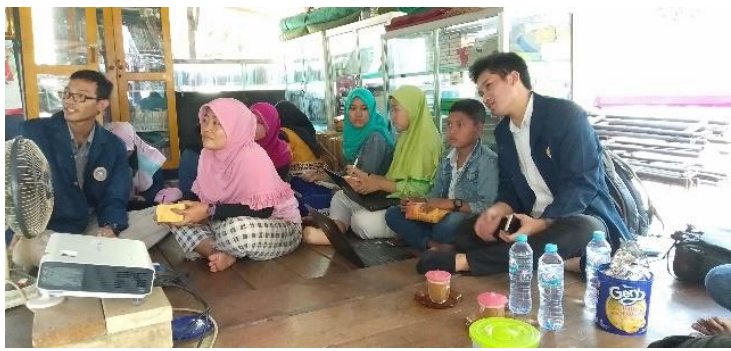

Gambar 4. Pembimbingan materi oleh mahasiswa

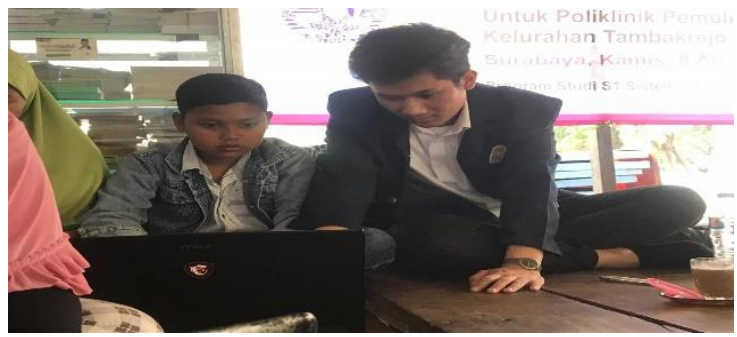

Gambar 5. Pembimbingan materi oleh mahasiswa (2)

Dalam pelaksanaannya, kegiatan ini terdapat beberapa support dan hambatan.

1. Support :

a. Antusiasme peserta dalam mengikuti dan mempraktekkan materi, hal ini menandakan motivasi peserta untuk menguasai materi.

b. Tim pakar dari tim pengabdian pada masyarakat yang memang telah sesuai dengan materi yang diajarkan.

2. Hambatan

a. Jumlah laptop yang terbatas, sehingga tidak semua calon peserta mendapatkan pinjaman laptop.

b. Lokasi yang sulit dijangkau karena terletak di dalam kompleks makam.

c. Tempat pelatihan yang sangat sempit, mengakibatkan banyak peserta yang berniat mau ikut menjadi batal.

Outcome dari kegiatan pengabdian pada masyarakat adalah peningkatan wawasan dan kompetensi dari admin poliklinik mengenai proses inventaris barang terutama mengenai pengelolaan inventarisasi, pengelolaan arsip dan aset dan memiliki kemampuan menggunakan aplikasi Sistem 
Informasi Inventaris Barang. Sebagai feedback, panitia melakukan diskusi dan wawancara kepada masyarakat yang mengikuti kegiatan mengenai pelatihan dan pendampingan yang telah dilakukan. Setelah itu dilakukan juga post test untuk mengukur kembali pengetahuan warga tentang microsoft excel setelah dilakukan pelatihan.

Berdasarkan hasil diskusi dan wawancara terhadap admin dan warga, disimpulkan bahwa kegiatan pengabdian kepada masyarakat ini mampu meningkatkan kompetensi admin poliklinik Pemulung. Selanjutnya warga berharap agar kegiatan semacam ini dapat dilanjutkan agar masyarakat dapat merasakan kebermanfaatan perguruan tinggi. Masyarakat berharap agar diadakan pelatihan sejenis seperti pelatihan aplikasi perkantoran, pembuatan akun dan cara penjualan online.

\section{KESIMPULAN}

Kesimpulan dari kegiatan pengabdian kepada masyarakat bagi admin poliklinik Pemulung di kawasan pemakaman Rangkah Surabaya, peserta antusias mengikuti kegiatan dari awal sampai dengan selesai. Selain itu, peserta dapat memahami materi yang diberikan dengan baik, hal ini terbukti dari peserta mampu mempraktekkan materi yang sudah diberikan. Kegiatan pengabdian masyarakat selanjutnya adalah pendampingan dalam mempraktekkan materi yang sudah diberikan untuk betul-betul digunakan dalam kegiatan inventaris. Harapan setelah dilaksanakan pelatihan adalah peserta memiliki pengetahuan dan ketrampilan yang dibutuhkan dalam melakukan inventarisasi, serta nantinya dapat bermanfaat dalam kegiatan sejenis lainnya.

\section{UCAPAN TERIMA KASIH}

Terima kasih kami ucapkan kepada
Lembaga Pengabdian dan Pengembangan
Masyarakat (LPPM) Unair yang telah memberikan kesempatan kami untuk dapat berbagi ilmu dan pengetahuan dan bantuan dana RKAT berdasarkan Surat Keputusan Rektor Nomor 1626/UN3/2019.

\section{DAFTAR PUSTAKA}

[1] F. Effendy and P. Purbandini, "Klasifikasi Rumah Tangga Miskin Menggunakan Ordinal Class Classifier," Jurnal Nasional Teknologi dan Sistem Informasi, vol. 4, no. 1, pp. 30-36, May 2018, doi: 10.25077/teknosi.v4i1.2018.30-36.

[2] J. S. Meiryani, Z. M. Daud, and S. M. Isa, "Inventory Information Systems of Health Equipment for the Need of Hospital Services," Journal of Talent Development and Excellence, vol. 12, no. 1, pp. 15341539, 2020.

[3] M. Martono, "Implementasi Prototype Aplikasi Pengelolaan Inventaris Barang," Jurnal Ilmiah Media Sisfo, vol. 13, no. 1, pp. 38-47, 2019.

[4] P. Sotiriadou, D. Logan, A. Daly, and R. Guest, "The role of authentic assessment to preserve academic integrity and promote skill development and employability," Studies in Higher Education, vol. 45, no. 11, pp. 2132-2148, 2020.

[5] A. Gutmans, S. S. Bakken, and D. Rethans, PHP 5 power programming. Prentice Hall PTR, 2005.

[6] F. Effendy, O. D. Kurniawati, and G. Priambada, "Factor Affecting E-Learning User Acceptance: A Case Study of AULA," in Journal of Physics: Conference Series, 2021, vol. 1783, no. 1, p. 12122.

[7] F. Effendy, E. Wuryanto, and L. F. Marentina, "Penerapan Model Technologyto-Performance Chain pada Cyber Campus," Jurnal Edukasi dan Penelitian Informatika (JEPIN), vol. 5, no. 2, p. 176, Aug. 2019, doi: 10.26418/jp.v5i2.32684. 